\title{
A família, a violência e a justiça \\ Conflitos violentos familiares, Lei Maria da Penha e concepções jurídicas no Tribunal de Justiça do Rio Grande do Sul
}

\author{
Family, violence and justice \\ Violent conflicts in the familiar context, Maria da Penha law and \\ juridical conceptions a the Tribunal de Justiça do Rio Grande do Sul
}

Fernanda Bestetti de Vasconcellos*

\begin{abstract}
Resumo: O presente artigo busca trazer dados acerca das modificações no ordenamento jurídico brasileiro, relacionadas com os processos de democratização e transformações sociais nas relações familiares no contexto nacional, no sentido de apresentar algumas das limitações burocráticas do estado em categorizar e legitimar diferentes configurações familiares. Para tanto, são observadas decisões judiciais apresentadas em diferentes âmbitos do Tribunal de Justiça do Rio Grande do Sul (TJ/RS) sobre conflitos de competências entre juizados criminais, de família e de infância e juventude para a administração de conflitos violentos familiares enquadrados pela Lei Maria da Penha.
\end{abstract}

Palavras-chave: Família. Violência familiar. Relações conjugais. Lei Maria da Penha.

\begin{abstract}
The present article aims bring data about changes in Brazilian law, related to the processes of democratization and social changes in family relationships in the national context, in order to present some of the shortcomings of the burocratic state in legitimize and categorize different family structures. To achieve this aim are observed court decisions presented in different scopes of the Court of Rio Grande do Sul on conflicts of jurisdiction between criminal courts, family courts and childhood courts for the administration of violent familiar conflicts framed by Maria da Penha Law.
\end{abstract}

Keywords: Family. Violence on familiar context. Conjugal relationships. Maria da Penha Law.

* Doutoranda em Ciências Sociais na Pontifícia Universidade Católica do Rio Grande do Sul (Pucrs), em Porto Alegre, RS, Brasil, bolsista Capes-Prosup e pesquisadora no Instituto de Estudos Comparados em Administração Institucional de Conflitos (INCT-InEAC) $<$ fevasconcellos@hotmail.com>.

\begin{tabular}{|l|l|l|l|l|l|}
\hline Civitas & Porto Alegre & v. 13 & n. 1 & p. 136-153 & jan.-abr. 2013 \\
\hline
\end{tabular}




\section{Introdução}

A partir da década de 1950, o modelo de família nuclear com tamanho reduzido (referindo-se a quantidade de filhos) começa a ser considerado um modelo adequado para as sociedades ocidentais. Neste movimento, o modelo familiar patriarcal passa a perder forças e um novo modelo democrático familiar ganha espaço, já que parece mais adaptado às condições urbanas modernas (Scott, 2004, p. 36). Pode-se dizer que é neste período também que a idéia do casamento fundado a partir do amor romântico é fortalecida, deixando de ter a economia como principal fundamento. Neste sentido, as famílias passam a viver um processo no qual deixam de ser uma unidade econômica e ainda que o número de mulheres inseridas em um mercado de trabalho seja ainda bastante reduzido, os direitos civis de homens e mulheres dirigem-se a um patamar de igualdade até então não atingido (Giddens, 2000, p. 66-67).

A família nuclear (formada por um casal heterossexual, unido pelo casamento, que cria seus filhos biológicos em coabitação) perde considerável espaço na vida social, tanto em termos estatísticos, quanto em termos normativos: o número de divórcios cresce no mundo todo, são incrementadas as estatísticas sobre famílias monoparentais, famílias formadas por casais homossexuais começam a ter sua legitimidade reconhecida, o casamento legal parece transformar-se mais em uma formalidade do que uma obrigação moral. Diferentes arranjos de família, abrangendo uma pluralidade de valores, são cada vez mais frequentes em sociedades permeadas por uma economia planificada plural (Fonseca, 2007, p. 9).

Provocada pelo debate acerca da legalização do casamento homossexual na França, Judith Butler (2003) aponta importantes questões a serem consideradas quando discutidas as categorias de conjugalidade e parentesco, no sentido de tentar evitar os riscos políticos e teóricos existentes na tentativa de circunscrever uma realidade bastante complexa. Neste sentido, cita que as conexões existentes entre estas categorias apresentam-se de diversas formas, e, dentre elas, relações de parentesco que não estão enquadradas no modelo de família nuclear e que não estão pautadas na ideia de relações biológicas e nãobiológicas, operando a partir de um regulamento que não pode ser formalizado, já que ultrapassa a possibilidade de alcance das concepções jurídicas.

De acordo com a autora, as relações de parentesco não fazem parte de uma esfera totalmente autônoma (uma vez são marcadas por vínculos de amizade e comunidade) e, ainda que muitas formas de parentesco não possam ser conhecidas e regulamentadas pelo estado, a força das práticas que 
estabelecem estas relações não é perdida. Neste sentido, a ideia de parentesco está ligada "a um conjunto de práticas que estabelece relações de vários tipos que negociam a reprodução da vida e as demandas da morte, então as práticas de parentesco são aquelas que emergem para dirigir as formas fundamentais da dependência humana" (Butler, 2003, p. 221-222).

Ao referir-se aos poderes de legitimação da vida social por parte do estado, a autora cita a capacidade limitada do mesmo para compreender as relações de parentesco, uma vez que estas relações sempre são categorizadas a partir de vínculos de casamento para serem consideradas viáveis, logo, legítimas.

Os poderes de normalização do estado se tornam, porém, especialmente claros, quando se considera o quanto a contínua perplexidade sobre o parentesco condiciona e limita os debates sobre casamento. Em alguns contextos, a alocação simbólica do casamento, ou arranjos similares, é preferível à alteração dos requisitos para que o parentesco proteja direitos individuais ou plurais de se ter ou de adotar crianças ou de assumir uma co-parentalidade legal. Variações no parentesco que se afastem de formas diádicas de família heterossexual garantidas pelo juramento do casamento, além de serem consideradas perigosas para as crianças, colocam em risco as leis consideradas naturais e culturais que supostamente amparam a inteligibilidade humana (Butler, 2003, p. 224).

Ao pensarmos na evolução das normas legais existentes no estado brasileiro, pode-se dizer que, de maneira geral, as mudanças no ordenamento jurídico nacional podem ser observadas como características de uma necessidade efetiva de acompanhar o processo dinâmico de transformações sociais. Desde a entrada em vigor do Código Civil de 1916 até a atualidade, os códigos jurídicos nacionais buscam abarcar as transformações da família, voltados para a necessidade estatal de formalização dos vínculos para o controle da ação social dos indivíduos. Neste sentido, pode-se observar um processo de mão dupla: o estado passa a reconhecer novas configurações familiares (através da sua legitimação pelo ordenamento jurídico) e os indivíduos, pertencentes às famílias, reconhecem a legitimidade da ação do estado.

$\mathrm{Se}$ os vínculos familiares forem considerados o principal mecanismo para que seja mantida uma ordem social (através da reprodução da estrutura do espaço e das relações sociais), é interesse primordial do estado a regulação de tais vínculos. Assim, o estado (através de seus agentes) cria categorias que estruturam as famílias, de modo a estabelecer quais elementos econômicos e sociais devem ser fortalecidos e quais indivíduos empoderados. 
Nesta perspectiva, ao mesmo tempo em que o agente estatal (neste caso, sendo considerados especificamente aqueles agentes pertencentes ao campo jurídico) possui legitimidade para dizer o direito, interpretando normas e tomando decisões, reproduz em seu discurso suas concepções pessoais (através de representações socialmente criadas) do que é uma família e como seus vínculos devem ser mantidos ou modificados. Assim, se considerada a existência de interpretações legais diversas e da construção de discursos jurídicos distintos (uma vez que os agentes do campo jurídico não possuem um pensamento monolítico), pode ser verificada a elasticidade das normas jurídicas e dos diferentes usos destas normas para a reprodução das concepções pessoais dos operadores do campo jurídico (Vasconcellos, 2010, p. 224).

Considerando-se os apontamentos acima dispostos, através de uma análise de como é realizada a administração de conflitos violentos familiares (ocorridos fora da dimensão conjugal entre casais heterossexuais) pelo Poder Judiciário do Rio Grande Sul, este artigo busca trazer dados que demonstrem a existência de uma luta interna ao campo jurídico, proveniente da disputa entre operadores do sistema, os quais norteiam suas práticas a partir da legislação (comum para todos), que buscam estabelecer através de seus discursos (baseados em suas concepções sociais) um conceito do que deve ou não ser considerada família pelo ordenamento legal. $\mathrm{O}$ artigo busca demonstrar também a presença de uma lógica burocratizante no sistema de justiça formal que possibilita que a caracterização de "incompetente" seja percebida como positiva e benéfica por muitos operadores jurídicos (quanto maior a incompetência jurídica, menos trabalho a ser feito). Para que seja realizada uma análise dos conflitos, são observados discursos jurídicos referentes a que grupos são ou não considerados família em casos relacionados à aplicação da Lei 11.340/06 (Lei Maria da Penha) e quais âmbitos do sistema de justiça formal são ou não competentes para julgar conflitos violentos domésticos e familiares que ocorrem fora das relações de conjugalidade heterossexual.

\section{As transformações na família moderna e o ordenamento jurídico brasileiro}

Ainda que o direito no Brasil tenha sofrido modificações tentando acompanhar a dinâmica das relações sociais, é necessário apontar aqui que este processo não ocorreu de forma 'natural': todas as transformações ocorridas foram impulsionadas pela busca de reconhecimento legal por parte de grupos sociais que procuraram, paulatinamente, ter suas relações familiares e/ou de conjugalidade tornadas legítimas pelo estado. Ainda que as estatísticas oficiais não produzissem dados que dessem conta das relações não reconhecidas 
formalmente pelo estado, pessoas uniam-se, separavam-se, viviam relações de concubinato e tinham filhos fora do casamento legalmente institucionalizado.

$\mathrm{O}$ ordenamento jurídico brasileiro sofreu algumas importantes modificações ao longo do século 20 e início do século 21, no que se refere à concepção legal do conceito de família. Até a instauração da Constituição Federal de 1988, as únicas normas que regiam o ordenamento familiar estavam dispostas em um Código Civil e algumas das transformações ocorridas na sociedade brasileira, desde então, passaram a influenciar modificações jurídicas.

Responsável pela regulação da família no início do século passado, o Código Civil de $1916^{1}$ reconhecia como legítima a família constituída unicamente a partir do vínculo de casamento. A família brasileira, a partir do Código Civil em vigor, era caracterizada como patriarcal, hierarquizada, patrimonializada e heterossexual: o homem exercia o comando da unidade conjugal, devendo ser respeitado e obedecido pela esposa e pelos filhos, tendo a família como finalidade conservar seu patrimônio, sendo necessária a geração de filhos para ser aumentada a força de trabalho. De acordo com o Código Civil de 1916, a dissolução do casamento era juridicamente impossibilitada e tanto casais unidos sem casamento, quanto filhos nascidos de uniões estabelecidas sem a formalidade exigida pelo estado eram discriminados.

O interesse estatal na manutenção do casamento levou, em um primeiro momento, à consagração de sua indissolubilidade e à obrigatória identificação da família pelo nome de varão. Ao casar, a mulher tornava-se relativamente incapaz, não podia trabalhar nem administrar seus bens. O regime da comunhão universal dos bens, como modelo oficial, mostra o significado que tinha o casamento. Duas pessoas fundiam-se numa só, formando uma unidade patrimonial, sendo o homem o único elemento identificador do núcleo familiar. O casamento não podia ser desconstituído, só anulado por erro essencial quanto à identidade ou à personalidade do cônjuge (Dias, 2010, p. 45).

Em 1962, é posto em vigor o Estatuto da Mulher Casada, ${ }^{2}$ o qual (diferentemente do que era exposto no Código Civil de 1916) estabelecia que a mulher casada passava a ter o direito de ser proprietária legítima dos bens adquiridos a partir da sua força própria de trabalho. Neste movimento,

1 O Código Civil de 1916. Disponível em: <http://www6.senado.gov.br/legislacao/ ListaPublicacoes.action?id=102644>.

2 A Lei 4.121 de agosto de 1962. Disponível em: <http://www.dji.com.br/leis_ordinarias/1962004121-emc/4121-62.html>. 
passam a ser observados com maior frequência o estabelecimento de novas uniões (não-oficiais) de indivíduos anteriormente desquitados (separados, mas com vínculo matrimonial mantido pelas leis). Assim, novas famílias são formadas por egressos de relacionamentos anteriores, sem a possibilidade de formalização legal.

A necessidade de rompimento do vínculo matrimonial anterior por parte dos casais e o interesse estatal em formalizar as novas configurações de relações conjugais impulsionam novas mudanças. Deste modo, em 1977, o divórcio passa a ser legalmente aceito pelo estado brasileiro, podendo este fato ser considerado como um marco legal de "dessacralização" da família brasileira (Dias, 2010, p. 30-31).

A legitimidade estatal de dissolução das famílias apresenta-se como um elemento que demonstra a existência de fortes transformações sociais que ocorriam na sociedade brasileira: o modelo de família nuclear e patriarcal passava por um processo de modificação e outros arranjos familiares começavam a ter uma visibilidade maior. Neste movimento, pode-se considerar a ideia de que a discussão em torno dos papéis individuais na família sofre um acirramento.

Procuram-se direitos, definidos e enfocados por meio de movimentos capazes de colocar holofotes sobre as demandas de seus participantes, e a família, devido à sua própria diversidade, se torna uma arena para a negociação e realização destes direitos, muito mais do que um sujeito de movimentos ou de investigação próprios (Scott, 2004, p. 45).

Na década de 1980, quando a Constituição Federal é promulgada, o Brasil experimenta um processo de redemocratização, a partir do qual os movimentos sociais voltados para a defesa de direitos individuais são fortalecidos. Com a entrada em vigor da Constituição Federal de 1988, a igualdade civil entre homens e mulheres é instaurada e o conceito de família ganha uma maior elasticidade, passando a proteger de modo igualitário todos os seus integrantes. Além disso, passa a ser legitimada pelo estado a união estável entre homem e mulher, deixando de ser o casamento civil a única forma considerada pelo mesmo.

[A Constituição Federal] Estendeu igual proteção à família constituída pelo casamento, bem como à união estável entre o homem e a mulher e à comunidade formada por qualquer dos pais e seus descendentes, que recebeu o nome de família monoparental. Consagrou a igualdade dos filhos, havidos ou não do casamento, ou por adoção, garantindo-lhes os mesmos direitos e qualificações (Dias, 2010, p. 31). 
No ano de 2003, um novo Código Civil entra em vigor no Brasil. Este novo Código busca realizar a atualização de aspectos importantes, relativos ao direito de família, incorporando modificações legislativas ocorridas anteriormente (por meio de legislação esparsa). O novo Código Civil (cujo projeto original já tramitava no Congresso Nacional antes mesmo da promulgação da Constituição Federal) tenta incorporar algumas das mudanças ocorridas na família brasileira durante o século 20, podendo ser citadas modificações ligadas à exclusão de referências desiguais entre homens e mulheres e entre filhos.

Ainda que os códigos jurídicos tenham tratado de um direito de família desde o Código Civil de 1916, nunca foi realizada a caracterização da mesma, a não ser pelo fato de citá-la como instituída após o casamento (ou união estável). Assim, qualquer vínculo com origem afetiva, responsável pela união de pessoas e de seus respectivos patrimônios, sofreria o risco de ser excluído do âmbito jurídico.

Neste sentido, as mudanças legais, que ocorrem pelas transformações sociais, passam por um processo de adequação às concepções de seus interpretes (os operadores do sistema de justiça), no sentido de construírem o que consideram a correta interpretação das leis. Tais interpretações podem variar de diversas formas, mas sempre serão dependentes de elementos ligados à construção das concepções individuais do significado legal e prático do que é uma família.

\section{Redemocratização brasileira, família e direitos individuais}

É a partir do processo de transição democrática que a constituição de movimentos sociais de defesa dos direitos humanos pode ser observada de modo crescente. Neste cenário, a busca pela garantia dos direitos civis de grupos sociais específicos impulsiona a elaboração da Constituição Federal de 1988 - chamada "Constituição Cidadã", cuja estruturação está baseada na afirmação de direitos humanos (Adorno, 2010, p. 7-9).

A partir dos anos 1970, o movimento feminista traz à tona o debate sobre a violência contra a mulher. Até esse momento, os acontecimentos vividos no âmbito doméstico marcados por violência não diziam respeito à polícia, justiça, vizinhança ou comunidade. Elementos como conservadorismo, patriarcalismo e sexismo permitiam que fosse mantida uma barreira quase intransponível entre o espaço público e o espaço privado (Soares, 1999, p. 27-28).

Juntamente com a crise do patriarcalismo e a "dessacralização" da família, as fronteiras entre espaço público e espaço privado passam a ter sua definição 
dificultada e a luta pela redefinição de conceitos como individualidade, direitos e responsabilidades é impulsionada pelos movimentos sociais. Neste sentido, atitudes e comportamentos familiares tradicionais vão sendo desnaturalizados e passam a ser classificados como crimes, violações e agressões que não podem mais ser toleradas pela sociedade.

Neste processo, o castigo físico, visto outrora como um legítimo recurso pedagógico, passa a ser considerado como uma modalidade possível de maus-tratos a crianças. O olhar malicioso, o comentário grosseiro e a sedução inconveniente criminalizam-se sob o título de assédio sexual. O contato sexual indesejado (ou não consentido) se incorpora ao leque dos delitos classificados sob a categoria de estupro, que passa a ser aplicada também à sexualidade conjugal (Soares, 1999, p. 30).

Com o objetivo de atender à demanda dos movimentos sociais que lutavam pelo acesso democrático a direitos civis, são realizadas algumas modificações no ordenamento jurídico brasileiro, as quais demonstram a necessidade de afirmação de individualidades e de igualdade, quando observadas as relações familiares. O que pode ser percebido não é uma crise da família enquanto local de referência ou de base para a sociabilidade, e sim uma crise do modelo familiar nuclear, patriarcal e hierárquico (Scott, 2004, p. 44-45).

No que se refere às mudanças no ordenamento jurídico brasileiro relativas às crianças e adolescentes, a partir da Constituição Federal são criados mecanismos de proteção e de definição dos mesmos como indivíduos portadores de direitos civis. A partir do que é expresso pelo artigo 229 da Constituição Federal de 1988, ${ }^{3}$ passa a ser dever imposto aos pais a assistência, criação e educação dos filhos menores (e aos filhos recai o dever de ajudar e amparar seus pais na velhice, carência e enfermidade). Outro ponto importante da Constituição está ligado ao reconhecimento da igualdade civil entre filhos legítimos e ilegítimos, já que passam a ter os mesmos direitos e qualificações, estando proibido qualquer tipo de discriminação entre eles (BuscherMaluschke, 2007, p. 89-90).

Em julho de 1990, entra em vigor o Estatuto da Criança e do Adolescente (ECA), ${ }^{4} \mathrm{o}$ qual passa a determinar tratamento específico às crianças (até 12

3 Art. 229. Os pais têm o dever de assistir, criar e educar os filhos menores, e os filhos maiores têm o dever de ajudar e amparar os pais na velhice, carência ou enfermidade. Disponível em: $<$ http://www.planalto.gov.br/ccivil_03/constituicao/constitui\%C3\%A7ao.htm>.

4 Lei 8.069, em vigor desde 13 de julho de 1990. Disponível em: <http://www.planalto.gov.br/ ccivil_03/Leis/L8069.htm>. 
anos de idade) e adolescentes (até 18 anos de idade), causando grande impacto no que se refere às políticas de atendimento aos seus destinatários, cujos direitos fundamentais passam a ser garantidos pela nova legislação, recebendo tratamento específico da justiça. A partir do ECA, são estabelecidos maiores direitos dos pais em relação aos filhos (e não mais poderes), fato que pode ser considerado como uma mudança na concepção jurídica tradicional de pátrio poder: a criança e o adolescente adquirem status de cidadãos plenos, com direitos que devem ser respeitados e protegidos, encarados como prioridade absoluta da sociedade civil (Miraglia, 2005, p. 93-95).

Outra mudança importante ocorre a partir da Lei no. 8.560, de 29 de dezembro de $1992,{ }^{5}$ que incumbe o Ministério Público de ministrar ações de investigação de paternidade, buscando a obtenção do reconhecimento do filho pelo pai nos casos de dúvida ou mesmo quando o reconhecimento voluntário é inviabilizado. Em período anterior à Lei, a consanguinidade como prova de filiação biológica não era aceita pelo sistema jurídico brasileiro, a não ser pela declaração voluntária da paternidade pelo próprio pai. Porém, com o desenvolvimento de novas tecnologias que permitem a determinação biológica da paternidade com exatidão, passam a ser necessárias mudanças no ordenamento jurídico, que começa a fazer uso destas tecnologias para garantir aos filhos a responsabilização civil dos pais (Buscher-Maluschke, 2007, p. 90).

É em um contexto que pode ser caracterizado como de busca pela redefinição das individualidades, dos direitos e responsabilidades, e das fronteiras que separam o espaço público do espaço privado que pode ser compreendida a criação da Lei no 11.340/06 (Lei Maria da Penha) no Brasil, a qual tenta dar conta do fenômeno da violência doméstica e familiar contra a mulher, responsável pela vitimização cotidiana de muitas mulheres no país, através da criminalização da violência.

Para Bárbara Soares, este processo de redefinições, no qual está inscrita a elaboração e entrada em vigor da Lei Maria da Penha, pode ser percebido de duas diferentes formas. A primeira delas está ligada a uma idéia de publicização do espaço privado, aumento do controle social (e das formas de dominação) e a uma racionalização da vida coletiva (marcada pela judicialização dos conflitos pessoais), onde a sociedade passa a possuir um caráter mais regulatório e opressivo, sendo que nem no espaço familiar (espaço privado) as relações estariam a salvo do controle externo legal. Neste sentido, a vida privada sofre uma espécie de institucionalização, sendo tomada por uma lógica burocratizante, comum à que rege a vida pública (Soares, 1999, p. 32-33).

\footnotetext{
5 A Lei no 8.560, de 29 de dezembro de 1992 está disponível em: <https://www.planalto.gov.br/ ccivil_03/leis/18560.htm>.
} 
Uma outra leitura possível é a da existência de um processo de redefinição de direitos, marcado pela expansão da democracia e pela extensão da individualidade. Neste movimento, ocorre a desnaturalização da vida social, no sentido de um rompimento com estruturas patriarcais e de tratamento da violência familiar como algo perverso e não natural. A partir desta leitura, vinculada a correntes feministas, o lar, o casal e a família perdem o caráter de mônadas impenetráveis e começam a ser considerados núcleos decisórios, autorreferidos e possuidores de direitos próprios, transformando-se em novas unidades socialmente significativas, onde seus integrantes competem legitimamente e em igualdade de condições pelo acesso aos direitos civis. De modo contrário ao que sugere a primeira leitura indicada pela autora, neste caso, o mundo privado estaria sobrepondo-se à esfera pública, através da imposição das suas temáticas e "contaminando-o com suas feridas, suas paixões, seus desejos, sua irracionalidade e selvageria" (Soares, 1999, p. 32-33).

O conceito de violência doméstica e familiar compreendido pela Lei Maria da Penha está disposto no Artigo 5:

Art. 5० Para os efeitos desta Lei, configura violência doméstica e familiar contra a mulher qualquer ação ou omissão baseada no gênero que lhe cause morte, lesão, sofrimento físico, sexual ou psicológico e dano moral ou patrimonial:

I - no âmbito da unidade doméstica, compreendida como o espaço de convívio permanente de pessoas, com ou sem vínculo familiar, inclusive as esporadicamente agregadas;

II - no âmbito da família, compreendida como a comunidade formada por indivíduos que são ou se consideram aparentados, unidos por laços naturais, por afinidade ou por vontade expressa; III - em qualquer relação íntima de afeto, na qual o agressor conviva ou tenha convivido com a ofendida, independentemente de coabitação.

Parágrafo único. As relações pessoais enunciadas neste artigo independem de orientação sexual.

De acordo com o texto da Lei, o âmbito familiar é aquele formado por indivíduos que possuem algum grau de parentesco biológico ou baseado em laços de amizade e/ou comunidade ("indivíduos que são ou se consideram aparentados, unidos por laços naturais, por afinidade ou por vontade expressa"). Neste sentido, a ideia de família parece estar relacionada com vínculos que ultrapassam relações conjugais entre um homem e uma mulher, independendo, também, da orientação sexual dos indivíduos envolvidos em casos de violência 
doméstica e familiar contra a mulher. A família citada na letra da Lei 11.340/06 não é caracterizada como aquela formalmente reconhecida pelo estado (a Lei não exige que os envolvidos nos conflitos abarcados possuam qualquer vínculo formal de casamento ou consanguíneo) e a ideia de parentesco exposta parece estar muito mais próxima dos vínculos descritos por Judith Butler e não daqueles formados somente a partir das relações conjugais entre casais heterossexuais.

\section{A administração dos conflitos familiares abarcados pela Lei 11.340/06 no judiciário gaúcho}

A partir da promulgação da Lei Maria da Penha, os conflitos violentos de gênero, ocorridos no âmbito doméstico ou familiar passam a ter sua administração nos Juizados de Violência Doméstica e Familiar contra a Mulher, os quais devem possuir competência tanto criminal quanto cível para atender às demandas das vítimas. ${ }^{6}$ Nos locais onde os Juizados não existirem, a competência para julgamento dos casos que envolvam violência doméstica e/ou familiar contra a mulher é atribuída à(s) vara(s) criminal(is) existente(s) na localidade. ${ }^{7}$

No caso do estado do Rio Grande do Sul, apenas um Juizado de Violência Doméstica e Familiar Contra a Mulher foi implementado desde a promulgação da Lei 11.340/06, sendo os casos de violência abarcados pela Lei ocorridos em locais fora da circunscrição do Juizado de competência de varas criminais. ${ }^{8}$ O Juizado de Violência Doméstica e Familiar Contra a Mulher da comarca de

\footnotetext{
6 Art. 13. Ao processo, ao julgamento e à execução das causas cíveis e criminais decorrentes da prática de violência doméstica e familiar contra a mulher aplicar-se-ão as normas dos Códigos de Processo Penal e Processo Civil e da legislação específica relativa à criança, ao adolescente e ao idoso que não conflitarem com o estabelecido nesta Lei.

Art. 14. Os Juizados de Violência Doméstica e Familiar contra a Mulher, órgãos da Justiça Ordinária com competência cível e criminal, poderão ser criados pela União, no Distrito Federal e nos Territórios, e pelos Estados, para o processo, o julgamento e a execução das causas decorrentes da prática de violência doméstica e familiar contra a mulher.

Parágrafo único. Os atos processuais poderão realizar-se em horário noturno, conforme dispuserem as normas de organização judiciária.

7 Art. 15. É competente, por opção da ofendida, para os processos cíveis regidos por esta Lei, o Juizado:

I - do seu domicílio ou de sua residência;

II - do lugar do fato em que se baseou a demanda;

III - do domicílio do agressor.

8 De acordo com a resolução 562/2006 do Conselho da Magistratura Gaúcha, disponível em: <http://google1.tjrs.jus.br/search?q=cache:www3.tjrs.jus.br/legisla/publ_adm_xml/ documento1.php $\% 3 \mathrm{Fcc} \% 3 \mathrm{D} 2 \% 26 \mathrm{ct} \% 3 \mathrm{D} 3 \% 26 \mathrm{ap} \% 3 \mathrm{D} 2006 \% 26 \mathrm{np} \% 3 \mathrm{D} 562 \% 26 \mathrm{sp} \% 3 \mathrm{D} 1 \% 26$ feed $\% 3 \mathrm{Dfeed}+$ artigo $+1 \% \mathrm{C} 2 \% \mathrm{BA} \% 2 \mathrm{C}+\mathrm{IV}+\mathrm{da}+$ Resolu $\% \mathrm{C} 3 \% \mathrm{~A} 7 \% \mathrm{C} 3 \% \mathrm{~A} 3 \mathrm{o}+\mathrm{n} \% \mathrm{C} 2 \% \mathrm{BA}+5$ $62 \% 2 F 2006 \&$ site $=$ tudo \&client $=$ buscaTJ $\&$ access $=$ p\&ie $=U T F-8 \&$ proxystylesheet $=$ buscaTJ $\&$ output=xml_no_dtd\&oe=UTF-8>. Acesso em: 12 jun. 2011.
} 
Porto Alegre foi criado em abril de 2008. De sua implantação até o momento, três juízes titulares, com diferentes percepções jurídicas a respeito da aplicação da Lei Maria da Penha (logo, com diferentes perspectivas a respeito do que seria uma correta administração dos conflitos violentos familiares contra a mulher) foram responsáveis pelo juizado.

Ainda que a Lei 11.340/06 seja aparentemente clara no que se refere à qual âmbito do judiciário é competente para administrar os conflitos familiares por ela abarcados, a prática dos operadores da justiça gaúcha apresenta diferentes interpretações sobre que âmbito do sistema de justiça deve ser responsável pela administração dos conflitos vividos em família e tipificados como referentes aos citados na Lei Maria da Penha. A "clareza" da letra da Lei passa a ser ofuscada a partir do momento em que é reconhecida a possibilidade de interpretação elástica de uma norma jurídica e que, em consequência de tal elasticidade, um mesmo conflito pode ser interpretado de diferentes formas.

Partindo-se da premissa de que não existe um conceito fechado e estanque de família, pode-se afirmar que esta categoria pode ser concebida de diversas formas. Assim, a ideia de "conflito violento familiar" pode ser compreendida de diversas formas pelos operadores jurídicos responsáveis pela administração deste tipo de conflito, uma vez que a interpretação da categoria "familiar" irá variar de acordo com as diferentes concepções jurídicas e sociais internalizadas que irão dar conta da compreensão do fenômeno. ${ }^{9}$

Para que a pesquisa sobre as diferentes concepções de família dos operadores da justiça no estado do Rio Grande do Sul pudesse ser iniciada, optou-se pela busca de documentos disponibilizados pelo site do Tribunal de Justiça do estado, ${ }^{10}$ no sentido de que pudessem ser verificados discursos acerca das diferentes concepções de família. Na página eletrônica da instituição é possibilitada a busca de documentos oficiais com conteúdo jurisprudencial, a partir de termos livremente escolhidos pelo usuário. Assim, foi realizada uma busca a partir do termo "11.340/06 + família". Foram encontrados 45 documentos diferentes, referentes a julgamentos ocorridos em segundo grau (pelas câmaras cíveis e criminais do TJ/RS) entre os meses de novembro de 2006 e dezembro de 2010.

A partir de uma primeira análise dos documentos encontrados, pode-se verificar que $73,3 \%$ (33 documentos) deles eram referentes aos pedidos de

\footnotetext{
9 Um outro ponto polêmico importante seria a definição do que configura ou não a "domesticidade" da violência contra a mulher. Porém, nos documentos analisados na primeira fase desta pesquisa, as discussões dos operadores jurídicos estavam centradas em torno do reconhecimento (ou não reconhecimento) do conflito violento como familiar, estando a categoria violência doméstica não contemplada pelos discursos.

${ }_{10}<\mathrm{http}: / /$ www1.tjrs.jus.br/site/>.
} 
análise de conflito de competência ${ }^{11}$ para o julgamento dos casos considerados pela Lei Maria da Penha. ${ }^{12}$ Optou-se, então, pela realização de uma análise mais aprofundada dos casos de conflitos de competência, nesta primeira fase da pesquisa.

Ainda que os documentos não possuam como característica grande extensão, o conteúdo dos discursos encontrados nos mesmos traz dados importantes acerca das disputas internas do campo jurídico a respeito de que âmbito possui a competência para administrar conflitos que podem ser considerados familiares por uma instância e por outra não. Na verdade, a dificuldade parece estar centrada em um exercício constante de classificações (o que é ou não família e que mulheres devem ou não ser beneficiadas pela Lei Maria da Penha) que, para serem realizadas, levam em conta, além da letra da Lei, critérios internalizados pelos operadores em suas diferentes dinâmicas sociais diárias.

Os conflitos narrados nos documentos analisados ocorrem entre operadores de Juizados Especiais Criminais, de Varas Criminais, de Varas de Infância e Juventude e de Varas de Família e Sucessões. Em todos os casos, a disputa está centrada na possibilidade de enquadrar ou não a violência ocorrida entre as partes em familiar ou não. São, principalmente, crimes de ameaça e agressão física, ocorridos entre mãe (em todos os casos vítimas) e filho(a), entre irmãos, avó e neta pequena, namorados e um casal homossexual. Acredita-se ser importante citar aqui que os pedidos de conflito de competência analisados parecem seguir uma lógica burocratizante, no sentido de afastar da "repartição" judicial suscitante a responsabilidade de administração de um determinado tipo de conflito social que, na prática, significa mais trabalho a ser realizado pelos servidores daquele local. Em nenhum momento o suscitante requer a competência para administrar um conflito que acredite ser de sua competência, mas, ao contrário, pede para que sua "incompetência" seja declarada por uma instância superior.

As argumentações dos operadores que redistribuem os processos para outros âmbitos do sistema judiciário (portanto, acreditam que a administração do conflito não seja de sua competência) variam muito, sempre de acordo com

\footnotetext{
${ }^{11} \mathrm{O}$ conflito de jurisdição ou competência poderá ocorrer entre autoridades judiciárias e o de atribuições entre autoridades judiciárias e administrativas. Dar-se-á conflito quando: a) ambas as autoridades se considerarem competentes; $b$ ) ambas se julgarem incompetentes; c) houver controvérsia entre as autoridades sobre a reunião ou separação de processos.

12 Os demais documentos encontrados são referentes a apelações ministeriais (6 casos); pedido de habeas corpus ( 1 caso); suspensão condicional do processo ( 3 casos) e agravo de instrumento ( 2 casos). Pretende-se, em uma próxima etapa da pesquisa, analisar estes documentos de modo mais aprofundado.
} 
o local de atuação. Nos casos em que juízes de varas criminais redistribuem os processos para os Juizados Especiais Criminais, por exemplo, as justificativas variam entre a impossibilidade de que seja configurada violência doméstica e familiar contra a mulher, quando vítima e agressora são mulheres, uma vez que, no entendimento de alguns operadores, não haveria opressão ao gênero, nem se trataria de vítima hipossuficiente ou vulnerável e o não enquadramento do conflito na Lei 11.340/06 pelo fato dos envolvidos não possuírem uma relação afetiva vinculada a casamento, união estável ou namoro, ainda que findados. Em todos os casos, há uma aparente dificuldade em relacionar a aplicação da Lei para conflitos familiares onde os envolvidos não possuem um vínculo de casamento ou namoro e possuam o mesmo gênero.

\section{Considerações finais}

A idéia de família é internalizada por todos os indivíduos durante sua socialização e reproduzida pelos mesmos indivíduos no decorrer de suas vidas. Assim, ao mesmo tempo em que família pode ser compreendida como um princípio de construção da realidade social, é ela própria socialmente construída e comum a todos os agentes sociais de alguma maneira.

De acordo com Pierre Bourdieu, se a palavra família for pensada somente como uma construção léxica, as representações sociais que os indivíduos (tanto especialistas, quanto integrantes do senso comum) possuem da mesma podem ser verificadas através de uma análise de seus diferentes discursos, marcados por ideologias políticas que valorizam determinadas relações sociais. A palavra família apresentar-se-ia, assim, como uma palavra de ordem (dito de outro modo, como uma categoria), a qual teria imbuído em seu sentido um princípio coletivo de construção de uma realidade social. O papel da família, enquanto mecanismo de manutenção da ordem social, é considerado por Bourdieu como primordial. Seu papel de reprodução não é apenas biológico, mas social, já que é responsável pela reprodução da estrutura do espaço social e das relações sociais (Bourdieu, 2003, p. 125-133).

O estado é o ente responsável na sociedade moderna pela criação de categorias oficiais que estruturam formalmente as populações, combinando elementos econômicos e sociais concretos para que seja privilegiada uma determinada forma de organização familiar. Neste movimento, todos aqueles indivíduos (ou agentes, como prefere chamar Bourdieu) capazes de conformarem-se moralmente com esta organização escolhida pelo estado são reforçados.

Assim, através da colocação em registros estatais, a família tem sua existência garantida e ratificada, de um ponto de vista bastante positivista, 
demonstrando uma realidade social através da existência de "uma vida em família" (o que seria a publicização de uma realidade privada).

De acordo com esta perspectiva, o espaço privado é, ao mesmo tempo, domínio estatal (ou público), já que a construção da idéia moderna de família é resultante da ação jurídico-política do estado. A visão pública (no sentido de uma visão legal) encontra-se profundamente misturada na visão privada, estando, as condutas privadas fortemente ligadas às ações públicas. Deste modo, ao mesmo tempo em que a idéia de família pode ser considerada uma ilusão, é, de fato, uma ilusão "bem-fundamentada", porque tem a garantia estatal para sua produção e reprodução.

Para Bourdieu, o direito é um reflexo direto das relações sociais que são orientadas de acordo com as forças nelas existentes, as quais determinam a ordem econômica de dada sociedade, sempre de acordo com os interesses das classes dominantes. Na verdade, o autor vê o direito como um instrumento de dominação, que adota um formalismo de maneira a afirmar a sua autonomia em relação à sociedade na qual está inscrito, mantendo as estruturas que permitem a criação e a acumulação de capital jurídico. A reivindicação da autonomia absoluta do pensamento e ação jurídicos baseiam-se no principio de que esses devem ser formados sem a interferência do meio social, bem como das pressões sociais, tendo no próprio direito seu fundamento.

O campo jurídico é um local no qual são travadas lutas de concorrência pela forma como deve ser dito e interpretado o direito. Assim, o agente social com mais força para vencê-la poderá interpretar leis e normas de forma reconhecida como legítima pelos outros atores do campo jurídico e, teoricamente, uma vez que Bourdieu acredita ser uma ilusão a existência da autonomia absoluta do direito, sem a pressão de interferências sociais externas (Bourdieu, 1989, p. 211-212).

Se partirmos das ideias de Bourdieu para pensarmos a realidade observada, podemos acreditar que, logicamente, as disputas internas referentes à qual âmbito do sistema judiciário possui competência para administrar qual conflito existentes no campo jurídico não são causadas pela entrada em vigor da Lei Maria da Penha. Na verdade, a disputa dos operadores jurídicos acerca da tipificação dos conflitos violentos familiares a partir da Lei 11.340/06 demonstra, de modo bastante mais explícito, a presença de uma fortíssima influência das concepções sociais destes operadores em suas tomadas de decisões. A construção destas concepções sociais é iniciada em um momento muito anterior à entrada destes agentes na profissão jurídica e, ainda que a construção legal tente diminuir ao máximo (através da letra da lei) a possibilidade de uma ampla utilização destas concepções 
subjetivas pelos operadores, não há como separá-las da prática do campo jurídico.

A dificuldade de criar um conceito estanque de família, que abarque todas as possíveis relações interindividuais existentes nas diferentes configurações destes grupos, também pode ser considerada como um elemento que possibilita a utilização de concepções sociais dos operadores jurídicos em suas práticas profissionais. Desta forma, pode-se dizer que a entrada em vigor da Lei Maria da Penha traz um novo desafio ao Poder Judiciário brasileiro, na medida em que tenta estabelecer uma espécie de unificação de competências jurídicas para tratar dos conflitos violentos familiares. Esta aposta, que visa administrar os conflitos de uma maneira mais ágil e de modo a reduzir os danos causados às partes nele envolvidas, na verdade, coloca diferentes âmbitos da estrutura rígida do campo jurídico em uma disputa fortíssima, ao invés de estabelecer a realização de um trabalho realmente unificado.

Partindo-se da análise dos documentos observados em uma primeira etapa desta pesquisa, pode-se pensar que o judiciário gaúcho não demonstra estar preparado para lidar com o processo de unificação de competências criminal e cível, no sentido de dar conta dos conflitos violentos familiares e domésticos que violem os direitos das mulheres, expostos na Lei Maria da Penha. A implementação de tal unificação parece dificultada pela existência de uma disputa interna ao campo jurídico (referente ao poder de dizer o direito), que pode ser observada a partir da tentativa recorrente dos magistrados no sentido de que a competência para administrar os conflitos violentos familiares seja renegociada. Além de trazer novos pontos de discussão entre os operadores jurídicos, a Lei Maria da Penha estabelece uma nova possibilidade de conflitualidade entre os diferentes âmbitos do sistema jurídico, uma vez que coloca a questão de gênero no cruzamento com conceitos de família, domesticidade e afetividade para tipificar violências e, em seguida, distribuir competências.

Neste sentido, as disputas entre os âmbitos dos Juizados Especiais Criminais, Varas Criminais, Varas de Infância e Juventude, Varas de Família e Sucessões e Juizados Especiais de Violência Doméstica e Familiar contra a Mulher parecem configurar-se, para além de uma disputa interna do campo jurídico sobre como deve ser interpretado o conceito de família, em ações político-ideológicas, as quais buscam limitar o conceito de família exposto pela Lei Maria da Penha àquelas relações que já foram reconhecidas e formalizadas pelo estado (ou que possuem as características necessárias para serem tornadas legítimas). Como consequência, a ideia fundadora da Lei 11.340/06 - defender os direitos das mulheres vítimas de violência doméstica e familiar de uma 
forma mais dinâmica e efetiva - é sobreposta por uma lógica burocratizante e limitada, a qual prioriza a concepção reduzida de família legítima e esquece das necessidades e direitos daquelas que buscaram o sistema de justiça formal para que seus conflitos fossem administrados.

\section{Referências}

ADORNO, Sérgio. História e desventura: o $3^{\mathrm{o}}$ Programa Nacional de Direitos Humanos. Novos Estudos Cebrap, São Paulo, n. 86, mar. 2010. Disponível em: $<$ http://www.scielo.br/scielo.php?script=sci_arttext\&pid=S010133002010000100001 \&lng $=$ pt\&nrm=iso $>$.

BOURDIEU, Pierre. O poder simbólico. Lisboa: Difusão Editorial, 1989. . A economia das trocas simbólicas. São Paulo: Perspectiva, 2003.

BUCHER-MALUSCHKE, Júlia Sursis Nobre Ferro. Revisitando questões sobre lei, transgressão e família em suas interações com a psicologia, a psicanálise, o direito e a interdisciplinaridade possível. Psicologia: Teoria e Pesquisa, Brasília, v. 23, n. esp., 2007. Disponível em: <http://www.scielo.br/scielo.php?script=sci_arttext\& pid $=$ S0102-37722007000500017\&lng $=$ pt\&nrm $=$ iso $>$.

BUTLER, Judith. O parentesco é sempre tido como heterossexual? Cadernos Pagu, Campinas, n. 21, 2003. Disponível em: $<\mathrm{http}: / / \mathrm{www} \cdot$ scielo.br/scielo.php?script=sci_ arttext\&pid $=$ S010483332003000200010\&lng=en\&nrm=iso $>$.

CÓDIGO Civil Brasileiro de 1916. Disponível em: <http://www6.senado.gov.br/ legislacao/ListaPublicacoes.action?id=102644>.

CONSTITUIÇÃO Federal de 1988. Disponível em: <http://www.planalto.gov.br/ ccivil_03/constituicao/constitui\%C3\%A7ao.htm>.

DIAS, Maria Berenice. Manual de direito das famílias. São Paulo: Editora Revista dos Tribunais, 2010.

FONSECA, Claudia. Concepções de família e práticas de intervenção: uma contribuição antropológica. Saúde social, São Paulo, v. 14, n. 2, ago. 2005. Disponível em: $<$ http://www.scielo.br/scielo.php?script=sci_arttext\&pid=S010412902005000200006 \&lng $=$ pt\&nrm=iso $>$.

. Conceito de entidade familiar e seguridade social. Porto Alegre: TRF - 4a Região, 2007 (Currículo Permanente. Caderno de Direito Previdenciário: módulo 3).

GIDDENS, Anthony. Modernidade e identidade. Rio de Janeiro: Jorge Zahar Editor, 2000.

LEI 4.121/62. Disponível em: <http://www.dji.com.br/leis_ordinarias/1962-004121emc/4121-62.html .

LEI 8.069/90. Disponível em: <http://www.planalto.gov.br/ccivil_03/Leis/L8069.htm>.

LEI 8.560/92. Disponível em: < https://www.planalto.gov.br/ccivil_03/leis/18560.htm>.

LEI 11.340/06. Disponível em: <http://www.planalto.gov.br/ccivil_03/_ato2004-2006/ 2006/lei/111340.htm>. 
MIRAGLIA, Paula. Aprendendo a lição: uma etnografia das Varas Especiais da Infância e da Juventude. Novos Estudos Cebrap, São Paulo, n. 72, jul. 2005. Disponível em: $<$ http://www.scielo.br/scielo.php?script=sci_arttext\&pid=S010133002005000200005 \&lng $=$ en $\&$ nrm $=$ iso $>$.

SCOTT, R. Parry. Família, gênero e poder no Brasil do Século XX. Revista Brasileira de Informação Bibliográfica em Ciências Sociais BIB, São Paulo, n. 58, p. 29-78, $2^{2}$ sem. 2004.

SOARES, Bárbara Musumeci. Mulheres invisíveis: violência conjugal e as novas políticas de segurança. Rio de Janeiro: Civilização Brasileira, 1999.

. Violência entre parceiros íntimos e a criminalização da vida privada: onde nos leva esse caminho? In: MORAES, Aparecida Fonseca; SORJ, Bila (Org.). Gênero, violência e direitos na sociedade brasileira. Rio de Janeiro: 7 Letras, 2009.

VASCONCELLOS, Fernanda Bestetti de. A prisão preventiva como mecanismo de controle e legitimação do campo jurídico. Rio de Janeiro: Lumen Juris, 2010.

Data de recebimento: 04/04/2012.

Data de aprovação: 30/03/2013.

Autora correspondente:

Fernanda Bestetti de Vasconcellos

Rua Conde da Figueira, 458, casa 3 - Vila Jardim

91330-590 Porto Alegre, RS 